\title{
Validating the Measures of Perceived Restorativeness in Obudu Mountain Resort, Cross River State, Nigeria
}

\author{
Henry I. Ojobo1,2, Sapura Mohamad1, Ismail Said1 \\ ${ }^{1}$ Department of Landscape Architecture, Universiti Teknologi Malaysia, Johor, Malaysia \\ ${ }^{2}$ Department of Architecture, Benue State Polytechnic, Ugbokolo, Benue State, Nigeria \\ Email: global bpc@yahoo.com, drsapura@gmail.com, ismailbinsaid@gmail.com
}

Received July 2014

\begin{abstract}
Several studies suggest that contact with natural environments enhance restoration of directed attention better than experience of other environments devoid of nature. This study attempts to validate the self-report measures of the components of a restorative environment and perceived stress through an exploratory study of the multi-stimulus Obudu mountain resort environment. Twenty-two respondents randomly co-opted at the study site had their perception of stress measured by the Perceived Stress Scale (PSS) while their perceived restoration was measured by the Perceived Restorativeness Scale (PRS). Results indicate an acceptable stable and consistent coefficient alpha across the scores. We found that perceived stress is significantly related to fascination and age while being away, extent, compatibility and length of days were not significant. The results support the reliability and constructs of the PSS and the PRS in a mountain environment. The finding is a further indication of the universality of the underlying postulates behind restorative environments, human response and wellbeing.
\end{abstract}

\section{Keywords}

Directed Attention, Stress, Restoration, Mountain Environments, Nigeria

\section{Introduction}

Researchers within the global north countries like the United States of America, Switzerland, Sweden and Greece have actively conducted studies on the psycho-physiological factors affecting stress and mental wellbeing [1]-[4]. Conversely, very few studies in this area have been carried out in the global south by researchers [5] [6] and Africa records the least. To ascertain the universality of restorative environments, human response and wellbeing, it is imperative to experiment with samples from Africa in order to add to the existing body of knowledge.

Studies examining the Attention Restoration Theory (ART) have steadily increased over the years [7]-[9] but research has not adequately juxtaposed perceived stress and the components of ART. According to Herzog et al., [10], restoration of attention capacity is dependent upon the four components of ART; (a) "Being away" which 
involves being in a setting that is different from everyday fatigue inducing environments; (b) "Extent” which describes any setting that has enough scope and organization to occupy the mind; (c) Fascination which specify an environment that evokes effortless attention; and (d) "compatibility" a purpose fit component. These four components are regarded by researchers evaluating encounters with natural environments as being supportive of restorative and therapeutic effects on humans. Perceived stress [11] has been variously measured by researchers using the psychometric properties of the perceived stress scale (PSS) [12]-[14] as developed and validated by Cohen et al. [15]. Cohen and his group assert that levels of appraised stress should be influenced by daily hassles, major events, and changes in coping events. It is however regarded as a state measure not a trait measure since the assessed items tend to focus on general issues rather than on event or experience specific issues. The authors regard the contact of respondents with the natural mountain environment as an experience specific event likely to influence the determination of perceived stress.

\subsection{Directed Attention and Restoration}

Several decades of research in the area of directed attention and stress restoration have accumulated a substantial and consistent body of research literature. Berto et al., [16] in retrospect posited that attention restoration environments where fascinating stimuli [17] are present can renew attention fatigue by inspiring effortless attention and allowing directed attention to rest and be restored. Attention enables the processing of vast quantities of information received by the visual system through the selection of subset of the received information for further processing depending on either the properties of the stimulus or on a voluntary choice by the subject [18]. Directed attention plays a major role in human capacity for selectivity in information processing and it is fragile, hence, capable of instigating fatigue and likely to precede incompetence or inappropriate behavior [9]. The consequences of directed attention fatigue include performance errors, irritability, uncouth behavior, and lack of concentration [10].

Nature seemingly has useful qualities for stress relief, mental restoration and enhanced mood generated through conscious or unconscious visual assessment [19] [20] of vegetation, foliage, trees, forests and water [21]. These characteristics are in short supply in our everyday urban settings [22] with antecedent stress promoting attributes of built structures, urban ambience, traffic and circulation. The benefits of a highly restorative nature experience [23] include erasing of mental noise, recovery of directed attention capacity [24] and ability to reflect on issues of importance [2].

\subsection{The Current Study}

The aim of this study is to validate the self-report measures of the four inherent components of a restorative environment through an exploratory study of the mountain environment as a cue for assessing the degree of each component on perceived stress. The sample consisted of 22 respondents who are expected to have engaged in stressful activities prior to visit and contact with the natural mountain environment. Psychological responses which represents the stress level of participants prior to visit to the mountain resort was measured using the PSS which is viewed as having concurrent validity and reliability [25] while restoration was measured by the PRS [26] [27] consisting four set of the attention restoration components which describes being away, extent, fascination and compatibility.

\section{Method}

\subsection{Survey Respondents}

The study sample consisted of 22 respondents (12 males, 9 females, 1 missing) randomly co-opted at the study sight. This was done by politely soliciting their attention, briefing them on the research purpose and finally getting them to fill the questionnaire. The age distribution was 36\% between 21 and 30 years, 36\% between 31 and 40 years, $9 \%$ between 41 and 50 years, 9\% between 51 and 60 years and $9 \%$ over 61 years. Sixty percent of the participants were married while $36 \%$ were single.

\section{Study Site and Stimuli}

This research involves an exploratory study of the Obudu mountain resort, Cross River state, Nigeria. The environment lies between latitude $6^{\circ} 21^{\prime} 30^{\prime \prime}, 6^{\circ} 22^{\prime} 30^{\prime \prime} \mathrm{N}$ and longitude $9^{\circ} 22^{\prime} 0^{\prime \prime}, 9^{\circ} 22^{\prime} 45^{\prime \prime} \mathrm{E}$ on an altitude of between 
$1700 \mathrm{~m}$ - $1765 \mathrm{~m}$ above sea level. It consists of diverse natural landscape attributes such as water fall, grotto, river, nature reserve, $70 \mathrm{~m}$ long canopy walkway suspended $60 \mathrm{~m}$ above forest ground level, bird watching, and the built structures which include the cable car for vantage point motion view and water theme park. Temperatures hover between $4^{\circ} \mathrm{C}$ to $23^{\circ} \mathrm{C}$ depending on the season and time of the year. A view of the resort environment from the cable car or the mountain vantage point reveals a vast layer of vegetation and beautiful waterscapes within the undulating topography.

\subsection{Measures and Instrument}

Psychological response which represents the stress level of participants prior to visit to the mountain resort was measured by the PSS. All the 14 items on the PSS were utilized with only a little revision on the construct of a few and also the erasure of 1 item due to printing error in the questionnaire (see Appendix 1 for current 13 item version). Perceived stress is viewed as an outcome variable which objectively measures stressful events and associated personality factors. Measured on a 5 point rating scale $(1=$ never; $5=$ very often), Participants scored each of the 13 items based on their feelings and thoughts within the month prior to their visit to resort.

Restoration was measured by the PRS predictor variable consisting four set of the attention restoration components which describes being away, extent, fascination and compatibility (see Appendix 2 for PRS version used). Measured on a 5 point rating scale ( $1=$ strongly disagree; $5=$ strongly agree) Participants scored items on each of the four predictor variables (being away, extent, fascination and compatibility) based on their experience and perception of the mountain resort environment.

\subsection{Procedure}

People who had spent less than 24 hours in the environment were exempted from participating in the survey. Respondents are expected to have engaged in stressful activities prior to visit and contact with the natural mountain environment. To ensure that respondents had already been in contact with most of the natural attributes of the environments they were recruited at the various locations of interest in the resort.

The survey took place in August 2013 with temperatures hovering between $15^{\circ} \mathrm{C}$ to $20^{\circ} \mathrm{C}$. Having obtained requisite approval from the resort authorities, the researcher engaged willing respondents with little effort. Total number of the three page questionnaire administered were 33, 25 were returned with 3 invalid response, 8 were not returned.

\section{Results}

Table 1 shows the result of a reliability test carried out as a first step to check if the scores from the PSS and the PRS were stable and consistent. The Coefficient alpha was used to test for internal consistency since the items on both instruments are scored as continuous variables. The items on the PSS recorded a Cronbach $\alpha=0.636$ while the 6 item of being away factor recorded a Cronbach $\alpha=0.684$, the 5 item extent factor recorded a Cronbach $\alpha=0.477$ and the 6 item fascination factor recorded a Cronbach $\alpha=0.554$. However, compatibility factor recorded the highest Cronbach $\alpha=0.706$. See appendix 1 for description of the items.

In addition, correlations between PSS and being away, extent, fascination, compatibility, age and length of days factors was then carried out to ascertain the strength and direction of association between the variables. As can be seen from the result in Table 2, the correlation coefficients show that PSS is significantly related to fascination $(r=0.539, \mathrm{P}<0.05)$ and age $(r=-0.588, \mathrm{P}<0.05)$. Other result, being away $(r=0.075, \mathrm{P}>0.05)$, extent $(r=0.046, P>0.05)$, compatibility $(r=0.079, P>0.05)$ and length of days $(r=0.200, P>0.05)$ were not significant. Overall, results show that the PSS with the PRS components were either strongly or moderately correlated.

Table 1. Cronbach Alpha Reliability coefficient for both PSS and PRS.

\begin{tabular}{cccccccc}
\hline & PSS & Being away & \multicolumn{2}{c}{ Extent } & \multicolumn{2}{c}{ Fascination } & Compatibility \\
\hline Crombach $\alpha$ & 0.636 & 0.684 & 0.477 & $\mathbf{0 . 6 3 4}$ & 0.554 & $\mathbf{0 . 6 1 4}$ & 0.706 \\
No. of items & 13 & 6 & 5 & $\mathbf{4}$ & 6 & $\mathbf{5}$ & 7 \\
\hline
\end{tabular}

Note: PSS—perceived stress scale; PRS—Being away, extent, fascination, compatibility. 
Table 2. Pearson Correlation of PSS, PRS, Age and Length of days of respondents.

\begin{tabular}{cccccccc}
\hline & PS & BA & EX & FA & CO & Age & LOD \\
\hline PS & 1.000 & & & & & & \\
BA & 0.075 & 1.000 & & & & & \\
EX & 0.046 & 0.146 & 1.000 & & & & \\
FA & $\mathbf{0 . 5 3 9}$ & 0.271 & 0.018 & 1.000 & & & \\
CO & 0.079 & 0.281 & 0.401 & 0.337 & 1.000 & & \\
Age & $-\mathbf{0 . 5 8 8}$ & 0.206 & 0.141 & -0.041 & 0.233 & 1.000 & \\
LOD & 0.200 & 0.085 & 0.283 & -0.026 & -0.272 & -0.090 & 1.000 \\
\hline
\end{tabular}

$\mathrm{R}$ values between + or -0.1 to 0.9 . Note: PS—Perceived stress; BA—Being away; EX—Extent; FA—Fascination; CO—Compatibility; LOD—Length of days; G-Gender.

\section{Discussion and Conclusion}

This study supports the reliability and constructs of the PSS and the PRS in a mountain environment. This is because an acceptable coefficient of the PSS and the PRS (being away, extent, fascination and compatibility) exists. The reliability test was based on data provided by the 22 respondents experiencing the mountain environment. Results show that internal consistency and stability of the items on the PSS is generally supportive. These reveal that the PSS is a valid psychological instrument for measuring stress.

On the other hand, result on some factors (extent and fascination) of the PRS structure was not consistent across all the scores. The relatively low consistency rating on the extent and fascination components was due to ambiguity and lack of clarity [28] of some questions. However, Crombach's alpha for being away and compatibility factors were marginally acceptable at 0.684 and 0.706 respectively. On the basis of the reliability analysis, items that reduce the Cronbach's alpha $(\alpha)$ with their inclusion were removed. With the removal of one item from the extent component which is 'this environment makes me feel like I am in a larger setting' a Crombach alpha of 0.634 is recorded while the removal of an item from the fascination component which is "this setting has many things that I wonder about” assumed to be ambiguous and unclear increases the Crombach alpha to 0.614. This shows that the two deleted items on the scales contributes to the inconsistency of the items (See Appendix 2 for revised PRS scale and items to be removed*).

An interesting outcome of this study is the correlation of the PSS and age on one side and PSS and fascination on the other. The negative correlation between PSS and age is in agreement with Cohen et al., [15] study which suggests that age was unrelated to PSS. This could portend that age is not a determinant of perceived stress. The reason for this is unclear but it is in our opinion that a further study using specific age groups may yield coherent answers. Another important finding was the acceptable correlation of PSS and fascination which was significant. It is possible that this result is due to the multi-stimulus nature of the Obudu mountain resort. Hence, drawing from [1] theoretical perspective, fascination apart from its intrinsic attraction is important to the restorative experience because it allows one to function without engaging directed attention.

The result of this study is a further indication of the universality of the underlying postulates behind restorative environments, human response and wellbeing. On the whole, we view the result of this exploratory study as a building block for the use of the PSS and PRS instruments in testing the restorative and stress mitigating benefits of natural mountain environments. However, the instruments were found to be convenient and easy to administer which is an indication of its usability on a larger population.

\section{References}

[1] Kaplan, S. (1992) The Restorative Environment: Nature and Human Experience. In: Relf, D., Ed., The Role of Horticulture in Human Well-Being and Social Development, Timber Press, Portland, 134.

[2] Herzog, T.R., Maguire, C.P. and Nebel, M.B. (2003) Accessing the Restorative Components of Environments. Environmental Psychology, 23, 159-170.

[3] Hansmann, R., Hug, S. and Seeland, K. (2007) Restoration and Stress Relief through Physical Activities in Forests and Parks. Urban Forestry and Urban Greening, 6, 213-225.

[4] Annersted, M., Norman, J., Boman, M., Mattsson, L., Grahn, P. and Wahrborg, P. (2010) Finding Stress Relief in a Forest. Ecological Bulletins, 53, 33-42.

[5] Sarkar, S. and Mukhopadhyay, B. (2008) Perceived Psychosocial Stress and Cardiovascular Risk: Observations among 
the Bhutias of Sikkim, India. Stress and Health, 24, 23-34.

[6] Tsunetsugu, Y., Lee, J., Park, B., Tyrvainen, L., Kagawa, T. and Miyazaki, Y. (2013) Physiological and Psychological Effects of Viewing Urban Forests Landscapes Assessed by Multiple Measurements. Landscape and Urban Planning, 113, 90-93. http://dx.doi.org/10.1016/j.landurbplan.2013.01.014

[7] Kaplan, S. and Berman, M.G. (2010) Directed Attention as a Common Resource for Executive Functioning and SelfRegulation. Perspectives on Psychological Science, 5, 43-57. http://dx.doi.org/10.1177/1745691609356784

[8] Chang, C.Y., Hammitt, W.E., Chen, P.K., Machnik, L. and Su, W.C. (2008) Psychophysiological Responses and Restorative Values of Natural Environments in Taiwan. Landscape and Urban Planning, 85, 79-84.

[9] Kaplan, S. (1995) The Restorative Benefits of Nature: Towards an Integrative Framework. Environmental Psychology, 15, 169-182. http://dx.doi.org/10.1016/0272-4944(95)90001-2

[10] Herzog, T.R., Hayes, L.J., Applin, R.C. and Weatherly, A.M. (2010) Compatibility: An Experimental Demonstration. Environmental Psychology, 43, 90-105.

[11] Bergdahl, J. and Bergdahl, M. (2002) Perceived Stress in Adults: Prevalence and Association of Depression, Anxiety and Medication in a Swedish Population. Stress and Health, 18, 235-241. http://dx.doi.org/10.1002/smi.946

[12] Pbert, L., Doerfler, L.A. and Decosimo, D. (1992) An Evaluation of the Perceived Stress Scale in Two Clinical Populations. Psychopathology and Behavioral Assessment, 14.

[13] Weekes, N.Y., Maclean, J. and Berger, D.E. (2005) Sex, Stress, and Health: Does Stress Predict Health Symptoms differently for the Two Sexes? Stress and Health, 21, 147-156. http://dx.doi.org/10.1002/smi.1046

[14] Lee, E.H. (2012) Review of the Psychometric Evidence of the Perceived Stress Scale. Asian Nursing Research, 6, 121-127.

[15] Cohen, S., Karmarck, T. and Mermelstein, R. (1983) A Global Measure of Perceived Stress. Health and Social Behavior, 24, 385-396. http://dx.doi.org/10.2307/2136404

[16] Berto, R., Baroni, M.R., Zainaghi, A. and Bettella, S. (2010) An Exploratory Study of the Effect of High and Low Fascination Environments on Attentional Fatigue. Environmental Psychology, 30, 494-500.

[17] Tennessen, C.M. and Cimprich, B. (1995) Views to Nature: Effects on Attention. Environmental Psychology, 15, 7785. http://dx.doi.org/10.1016/0272-4944(95)90016-0

[18] O’Craven, K.M., Rosen, B.R., Kwong, K.K., Treisman, A. and Savoy, R.L. (1997) Voluntary Attention Modulates Fmri Activity in Human MT-MST. Neuron, 18, 591-598. http://dx.doi.org/10.1016/S0896-6273(00)80300-1

[19] Grinde, B. and Patil, G.G. (2009) Does Visual Contact with Nature Impact on Health and Well-Being. International Journal of Environmental Research and Public Health, 6, 2332-2343. http://dx.doi.org/10.3390/ijerph6092332

[20] Cole, D.N. and Hall, T.E. (2010) Experiencing the Restorative Components of Wilderness Environments: Does Congestion Interfere and Does Length of Exposure Matter. Environment and Behavior, 42, 806-823. http://dx.doi.org/10.1177/0013916509347248

[21] Bulut, Z., Karahan, F. and Sezen, I. (2010) Determining Visual Beauties of Natural Waterscapes: A Case Study of Tortum Valley. Scientific Research and Essay, 5, 170-182.

[22] Thompson, C.W. (2011) Linking Landscape and Health: The Recurring Theme. Landscape and Urban Planning, 99, 187-195. http://dx.doi.org/10.1016/j.landurbplan.2010.10.006

[23] Hartig, T., Berg, V.D., A.E., Hagerhall, C.M., Tomalak, M., Bauer, N., Hansmann, R., Ojala, A., Singolliton, E. and Carrus, G. (2011) Health Benefits of Nature Experience: Psychological, Social, and Cultural Processes. Forests, Trees and Human Health.

[24] Laumann, K., Garling, T. and Stormark, K.M. (2003) Selective Attention and Heart Rate Responses to Natural and Urban Environments. Environmental Psychology, 23, 125-134.

[25] Andreou, E., Alexopoulos, E.C., Lionis, C., Varvogli, L., Gnardellis, C., Chrousos, G.P. and Darviri, C. (2011) Perceived Stress Scale: Reliability and Validity Study in Greece. Environmental Research and Public Health, 8, 32873298.

[26] Hartig, T., Korpela, K., Evans, G.W. and Garling, T. (1997) A Measure of Restorative Quality in Environments. Scandinavian Housing \& Planning Research, 14, 175-194. http://dx.doi.org/10.1080/02815739708730435

[27] Laumann, K., Garling, T. and Stormark, K.M. (2001) Rating Scale Measures of Restorative Components of Environments. Environmental Psychology, 21, 31-44.

[28] Creswell, J.W. (2012) Educational Research: Planning, Conducting, and Evaluating Quantitative and Qualitative Research. 4th Edition, Pearson Education Inc., USA. 


\section{Appendix 1}

The perceived stress results are based on the Cohen et al., 1983 version of the perceived stress scale comprising of 14 items below. Participants made their responses using a 5-point Likert scale to indicate their feelings and thoughts during the last month ( 1 = Never; 5 = Very often).

1. How often have you been upset because of something that happened unexpectedly?

2. How often have you felt that you were unable to control the things in your life?

3. How often have you felt nervous and "stressed"?

4. How often have you dealt successfully with day to day problems and annoyance?

5. How often have you felt that you were effectively coping with important changes that were occurring in your life?

6. How often have you felt confident about your ability to handle your personal problems?

7. How often have you felt that things were going your way?

8. How often have you found that you could not cope with all the things that you had to do?

9. How often have you been able to control irritations in your life?

10. How often have you felt that you were on top of issues?

11. How often have you been angered because of things that happened that where outside of your control?

12. How often have you found yourself thinking about things that you have to accomplish?

13. How often have you been able to control the way you spend your time?

14. How often have you felt difficulties were piling up so high that you could not overcome them?

\section{Appendix 2}

Perceived restoration results were based on the Hartig et al., 1997 version of the perceived stress scale comprising of 4 factors with 24 items below. Participants made their responses using a 5-point Likert scale to indicate their experience and perception of the environment ( 1 = strongly disagree; $5=$ strongly agree).

\section{Being away}

1. I am in a different environment than usual.

2. I engage in activities different than I usually.

3. I feel free from work and routine.

4. I feel free from other people's demands and expectations.

5. I do not need to think of my responsibility while am here.

6. I am away from my obligations.

\section{Extent}

1. The elements here go together.

2. The size of this place affords me the opportunity to discover and explore many things.

3. I can see all parts of this setting without obstruction or interference.

4. This environment makes me feel like I am in a larger setting*

5. It takes me a lot of time to fully appreciate this environment.

\section{Fascination}

1. There are many things here that I find beautiful.

2. There is plenty that makes me want to continue staying here.

3. This setting has many things that I wonder about ${ }^{*}$.

4. There are many elements here that attract my attention.

5. I am absorbed in these surroundings.

6. I don't require effort for the environment to engage my attention.

\section{Compatibility}

1. There is an agreement between what I like to do and these surroundings.

2. The environment gives me the opportunity to do activities that I like.

3. This place supports my intended desires.

4. This place is comfortable and pressure free for me.

5. This environment is well organized.

6. The built structures here fit the type of environment.

This place does not place demands on me to act in a way I would not want. 